\title{
Training of Public Extension Agents in Nigeria and the Implications for Government's Agricultural Transformation Agenda
}

\author{
Haruna S.K. and Abdullahi Y.M.G \\ National Agricultural Extension Research Liaison Services (NAERGLS), \\ Ahmadu Bello University, PMB 1067 Samaru-Zaria, Nigeria \\ E-mail: salisukura@gmail.com Mobile: 08026929746
}

\begin{abstract}
The paper reviewed and analyzed the findings from five years of ADPs and Agricultural field situation survey conducted by NAERLS and NFRA. The study examined the pattern and scope of training needs in the public sector extension in Nigeria, EA: FF ratio, problems and prospects of conducting training and the implications of all these for the current government's Agricultural Transformation Agenda (ATA).
\end{abstract}

Key words: Training needs, Extension agent

\section{Introduction}

Nigeria's national agricultural policy of 1988 was premised on the expected role of the economy. The goal of the policy was the structural transformation socio-economic development in Nigeria's rural areas. The specific objectives of the policy were the attainment of self-sufficiency in basic food commodities, increase production of agricultural raw materials, integrated agricultural and rural development and combating environmental threats to food security (Idachaba, 1988, in Albert and Isife, 2009).

Similarly every organisation is built and filled with human resources to serve specific purpose within the context of a policy and mission. In recent years, the extension systems have been increasingly criticized for being not that effective for all the investment that has gone into maintaining its organization and staffing (Qamar, 2005). Public institutions are funded with the public funds and as such are supposed to serve the public. In the case of agricultural extension, the organization is meant to serve the extension, education and training needs of both EAs and farmers (Qamar, 2005). If it is established that the organization is not delivering effectively and efficiently what it was built to deliver, then transformation becomes very necessary. A quick way will be to assess it on the basis of extension and the provision of training to its extension personnel and the farming communities.

This idea is in line with Coutts et.al.'s (2005) affirmation that, success of any programme depends largely on the quality, characteristics and skills of planners and implementers. For the agricultural sector to contribute its share to the economic development of the country; local institutions staffed by trained manpower are essential. Rapid agricultural development requires large number of EAs and farmers whose capacity is developed to understand and solve agricultural production problems.

One of the overall goals of the Agricultural Extension Transformation Agenda is to develop well-trained and motivated staff that will effectively cater for a variety of actors along targeted value chains of interest to the state and federal government. However, a key challenge facing the nation's largest public provider of extension services, the Agricultural Development Programmes (ADPs), which has seriously limited their performance and affected the productivity of farmers, is inadequate and poor quality of staff. This is the context in which this paper intends to examine the problems of inadequate extension agents; farm families ratio, extension agents (EAs) training, and the likely causes of the problem across the nation's ADPs. 
The implications of the situation for the federal government's Agricultural Transformation Agenda (ATA) were analysed and appropriate measures recommended.

\section{Methodology}

Secondary data used for this study was obtained mainly from reports of the National Agricultural Performance Surveys (APS) conducted jointly by the National Agricultural Extension and Research Liaison Service (NAERLS) and the National Food Reserve Agency (NFRA in collaboration with several other institutions in Nigeria, from 2008 to 2011.

The scope of information gathered include; EA:FFs ratio, their training needs and problems of extension services closely affecting the staffing and staff training and development in the ADPs in Nigeria. Similarly, the Federal Government's ATA mission and vision were reviewed for the purpose of the study.

\section{Findings and Discussion}

\section{Availability and Training of Extension Agents in ADPs in Nigeria}

\section{Extension Agent: Farm Families Ratio}

Front line extension agent is a key to the success of any extension service delivery organization because they have direct contact with end-users of any farming technology. Based on their importance as strong actors in transforming agriculture, it's recommended by FAO that one extension agent should serve a maximum of one thousand (1000) farm families in developing countries.

However, a five (5) years trend of EA: farm families ratio across the country in Table 1 shows that;in 2008 Anambra, Ebonyi and Kwara has the lowest EA:Farmer ratio of 1:6048, 1:6046 and1:4025 while Ekiti, Oyo, Enugu and Delta has highest ratio of 1:42,1:500,1:746 and1:800 respectively. In 2009 the survey marked Sokoto, Kwara, Anambra and Benue as states with largest of farm families per EA with; 1:4013, 1:3843, 1:3799 and1:3640 while Oyo, FCT and Delta were proved to have the lowest farm families per EA of 1:42, 1:170 and1:800 correspondingly. Year 2010 shows that Anambra, Rivers, Enugu, Cross River, Sokoto and Kwara has 1:9409, 1:6748, 1:6013, 1:4458, 1:4050, 1:4000 EA:farm families ratio accordingly, while Adamawa and Yobe have1:1000 each.

Table 1 also revealed that in 2011 Anambra, Enugu and Rivers States has the highest EA:Farmer ratio with 1:9407, 1:6848 and 1:6749 respectively. While states like Oyo, Kano and Kogi has 1:800, 1:844 and 1:1000 respectively. The 2012 survey pointed out Bayelsa, Anambra, Cross River and Benue as states has the highest number of farmers per single extension agent; 1:10,568, 1:9409,1:4721 and 1:4000 respectively. Oyo state appears to be the state with low EA; farmer of 1:800 while Kogi and Imo have 1000 each. On the average and across Nigeria, the ADPs EA: FFs ratio oscillated from 1:1700, 1:2132, 1:3385, 1:2950 and1: 3011 between the years 2008 and 2012 (APS 2008-2012).

In each of the States, the large ratio was highly interconnected to the low number of frontline EAs on ground. This trend of diminishing number of VEAs had persisted over the years because most ADPs could not recruit new VEAs even with the dire needs. As inadequacy is a serious issue that inhibits effective dissemination of new and useful information of agricultural technologies. In this kind of situation, the authorities of extension organisation should urgently find means of recruiting adequate and qualified EAs. Where rescuing the problems become a challenge due to weak or poor funding, those EAs on ground should be well trained and develop their capacity on how to effectively interacts with farmers through their groups. 
Table 1: Nigeria's Extension Agent: Farm Families ratio, 2008 - 2012

\begin{tabular}{|c|c|c|c|c|c|}
\hline \multirow[t]{2}{*}{ State } & \multicolumn{5}{|c|}{ EA: farm families ratio trend } \\
\hline & 2008 & 2009 & 2010 & 2011 & 2012 \\
\hline Borno & $1: 1971$ & $1: 1971$ & NA & $1: 1964$ & $1: 1964$ \\
\hline Yobe & $1: 1800$ & $1: 1800$ & $1: 1000$ & $1: 2472$ & $1: 2472$ \\
\hline Bauchi & $1: 1300$ & $1: 1300$ & $1: 1700$ & NA & $1: 1731$ \\
\hline Gombe & $1: 1350$ & $1: 1741$ & $1: 1225$ & $1: 1225$ & $1: 1225$ \\
\hline Adamawa & $1: 2549$ & $1: 2459$ & $1: 1000$ & $1: 1212$ & $1: 1212$ \\
\hline Jigawa & $1: 1500$ & $1: 1500$ & $1: 1389$ & $1: 2054$ & NA \\
\hline Katsina & NA & NA & NA & $1: 3000$ & $1: 3000$ \\
\hline Sokoto & NA & $1: 4013$ & $1: 4050$ & $1: 4050$ & $1: 4000$ \\
\hline Kebbi & $1: 1600$ & $1: 3749$ & $1: 3749$ & $1: 2608$ & NA \\
\hline Zamfara & $1: 1490$ & $1: 1400$ & $1: 1479$ & $1: 1944$ & $1: 1944$ \\
\hline Kano & NA & NA & NA & $1: 844$ & NA \\
\hline Kaduna & $1: 3000$ & $1: 3000$ & NA & $1: 3240$ & $1: 3240$ \\
\hline Taraba & $1: 3200$ & $1: 3200$ & $1: 3200$ & $1: 3200$ & $1: 3200$ \\
\hline Plateau & $1: 1000$ & $1: 1800$ & $1: 3038$ & $1: 3187$ & NA \\
\hline Nasarawa & $1: 2313$ & $1: 3200$ & $1: 1317$ & $1: 1156$ & $1: 1368$ \\
\hline FCT & $1: 1148$ & $1: 1700$ & $1: 1282$ & NA & NA \\
\hline Niger & $1: 2280$ & $1: 2160$ & $1: 3000$ & $1: 2000$ & $1: 2000$ \\
\hline Kwara & $1: 4025$ & $1: 3843$ & $1: 4000$ & $1: 2500$ & $1: 2190$ \\
\hline Kogi & $1: 1526$ & $1: 1526$ & $1: 2160$ & $1: 1000$ & $1: 1000$ \\
\hline Benue & $1: 2630$ & $1: 3640$ & $1: 1747$ & $1: 3500$ & $1: 4000$ \\
\hline Oshun & $1: 3217$ & $1: 3097$ & NA & $1: 1984$ & $1: 1984$ \\
\hline Oyo & $1: 500$ & $1: 500$ & $1: 3773$ & $1: 800$ & $1: 800$ \\
\hline Ekiti & $1: 42$ & $1: 42$ & $1: 2750$ & $1: 3000$ & $1: 3000$ \\
\hline Ogun & $1: 3711$ & $1: 3711$ & $1: 2812$ & $1: 3364$ & $1: 3364$ \\
\hline Lagos & $1: 1100$ & $1: 1350$ & $1: 1612$ & $1: 1612$ & $1: 1612$ \\
\hline Edo & $1: 2100$ & $1: 2100$ & $1: 3750$ & $1: 3750$ & $1: 3750$ \\
\hline Delta & $1: 800$ & $1: 800$ & $1: 1559$ & $1: 1559$ & $1: 1559$ \\
\hline Ondo & $1: 1500$ & $1: 1500$ & $1: 1480$ & $1: 1480$ & NA \\
\hline Anambra & $1: 6048$ & $1: 3799$ & 1:9409 & 1:9409 & 1:9409 \\
\hline Enugu & $1: 746$ & $1: 850$ & $1: 6013$ & $1: 6848$ & $1: 3081$ \\
\hline Ebonyi & $1: 6046$ & $1: 1960$ & NA & NA & NA \\
\hline Cross river & NA & NA & $1: 4458$ & $1: 4013$ & $1: 4721$ \\
\hline Rivers & NA & NA & $1: 6748$ & $1: 6749$ & $1: 3450$ \\
\hline Abia & $1: 2632$ & 1:2952 & $1: 2700$ & $1: 2700$ & $1: 2700$ \\
\hline Akwa Ibom & NA & NA & $1: 3086$ & $1: 3086$ & $1: 2902$ \\
\hline Imo & $1: 3333$ & $1: 3333$ & NA & $1: 1300$ & $1: 1000$ \\
\hline Bayelsa & NA & NA & NA & $1: 10,568$ & $1: 10,568$ \\
\hline $\begin{array}{l}\text { Year average EA:FFs } \\
\text { ratio }\end{array}$ & $1: 1700$ & $1: 2132$ & $1: 3385$ & $1: 2950$ & $1: 3011$ \\
\hline
\end{tabular}

Source: NAERLS Field survey

Training of Extension Agents

Knowledge and awareness are considered prerequisites for adoption of new technologies; similarly change agent success in securing adoption is related to clients' perception of change agent credibility (Rogers, 1995). Thus, extension agent knowledge and practical competence is a vital resource in the implementation of extension policy. The provision of in-service educational and training programs prior to program delivery is one strategy for improving extension agent competence and credibility. 
However, the finding showed that in most of the ADPs the provision of staff training and development programmes are very inadequate and limited to a few staff. Table 2 portray the most needed trainings by ADPs like; Pre-season, post-season \& other refresher trainings, management training for administrative staff ,extension communication skills, group formation and development, data gathering skills, training on research methodology, crop improvement and pests \& diseases management and use of computer, web and other ICTs in agriculture, short courses and the full time training courses/degree programmes which are believed to improve the capacity and productivity of EAs. The request for ICT skills made by ADPs is in agreement with a study (Ssekiboobo and Muwanga-Zake, 2013) who observed that lack of ICT training among extension staff in developing countries inhibits their capacity for collection and handling of agricultural data and statistics and consequently contributes to the limited supply of agricultural statistical data and services to meet data user needs. Other training needs according to the finding which agreed to influence the quality of EAs considers the assertion of Coutts et al. (2005) who affirmed that extension activities are largely affected by quality, characteristics and skills of those who plan and implement the programmes.and for; local institutions stuffed by trained man power is essential.

Since frontline extension agent's skills and capacity are closely related to the broader dissemination and adoption of new and improved agricultural technologies, the training needs for 2008 to 2011 presented in table 2 must be attained. This would move agricultural sector forward to contribute its share to the economic development of the country

Table 2

Training needs of ADP extension staff in Nigeria, from $2008-2011$

\begin{tabular}{llrl}
\hline Years & Training Subject Matter & No. of ADPs & \%Percentage \\
\hline 2008 & Extension communication skills & 11 & 29.7 \\
& Radio and TV programme, report writing & 8 & 21.6 \\
& Computer/ICT, & 7 & 18.9 \\
& Pre-season training & 13 & 35.1 \\
& Safe use of agrochemical & 9 & 24.3 \\
& Group formation and development & 15 & 40.5 \\
& Pre-season training & 26 & 70.2 \\
& Long and short term course & 19 & 51.3 \\
& Management training for admin staff & 19 & 51.3 \\
& data gathering skills & 7 & 18.9 \\
& Extension communication skills & 11 & 29.7 \\
& Specialised training for SMSs & 16 & 43.2 \\
& Fish farming technology & 11 & 29.7 \\
& Pre-season training & 16 & 43.2 \\
& Popularization of artificial insemination & 11 & 29.7 \\
& Seed production and certification & 16 & 43.2 \\
& Extension communication skills & 6 & 16.2 \\
& Agric project planning and management & 9 & 24.3 \\
& Participatory training techniques & 6 & 16.2 \\
& Crop improvement & 12 & 32.4 \\
& pests \& diseases management & 12 & 32.4 \\
& Pre and post-season \& other refresher & & \\
& trainings & 13 & 35.1 \\
& Use of Computer, Web and other ICTs & 13 & 35.1 \\
\hline
\end{tabular}

Source: NAERLS2008-2011 
Analyzing the training needs based on geo-political zones of the country, Figure 1 shows that in 2011 , on the average North Central geopolitical zone indicated higher number $(62 \%)$ of extension workers needing training, followed by North-East geopolitical zone with about $48 \%$. Conversely, the North-Western zone indicated the least (10\%) need for their extension staff training. The variations in number of extension workers needing training may be related to non-regular conduct of training by ADPs in the zones, due to poor and late release of fund resulting to lack proper training schedule in its work plan.

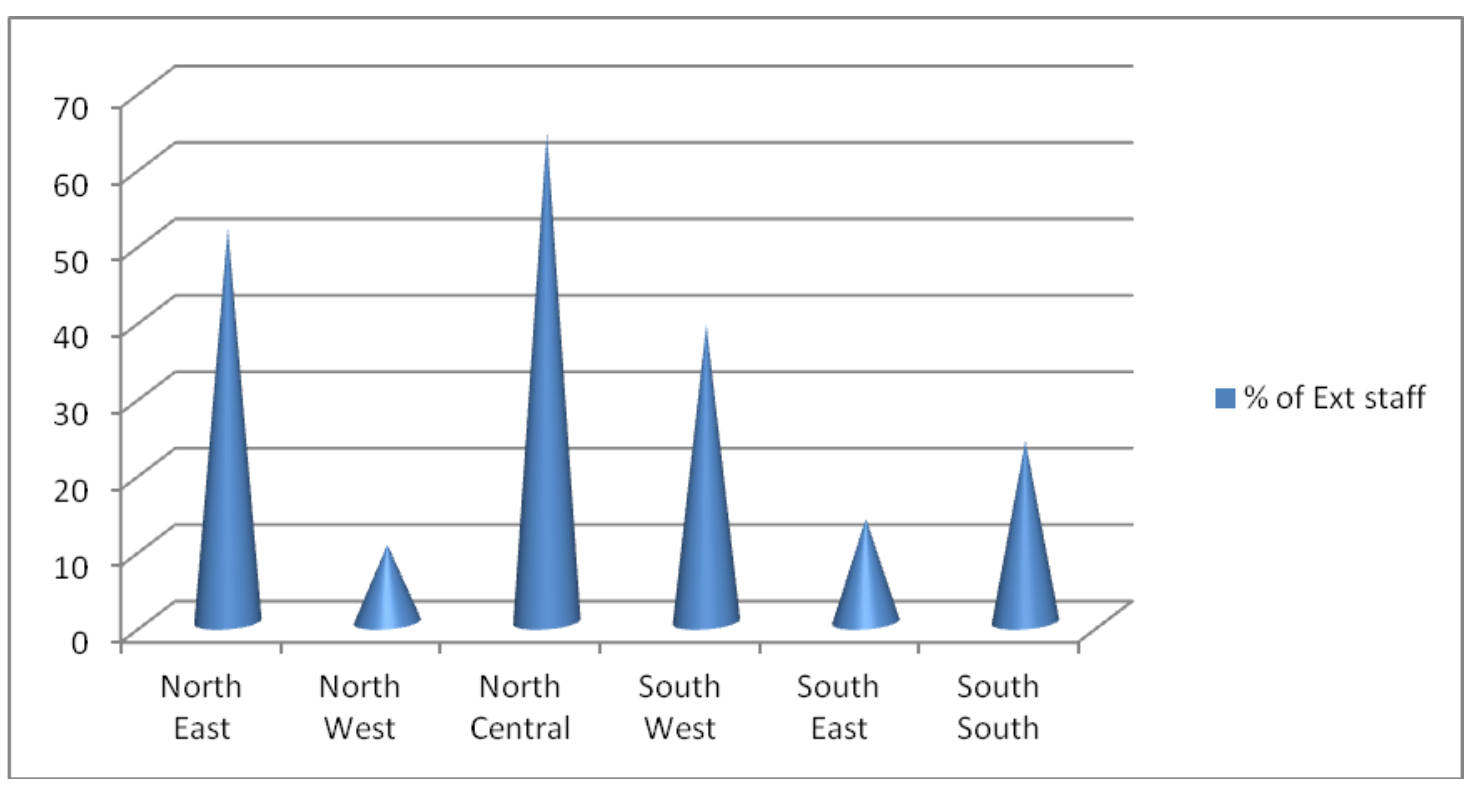

Figure 2: Proportion of extension staff needing training according to geo-political zones of Nigeria (Source: NAERLS 2011)

\section{Major Contributor to the Staffing and Staff Training Problems Funding of ADPs in Nigeria}

Funding is very fundamental for efficient and effective performance and attainment of any organizational goals. Figure 1 showed funding status of Nigeria's ADPs from 2008 to 2011. Majority $(75.1 \%)$ of the ADPs are inadequately funded, while only about $14 \%$ of them were adequately funded. This finding is in line with Auta and Dafwang (2012) finding which pointed out that Nigeria's ADPs is poorly funded and where fund is allocated for its activities it is not release in time. Funding in adequacy and its untimely release is found to be the most pressing problems against the conduct of trainings in most of extension delivery institutions in the country and consequently inhibits any forward moving agricultural programmes. 


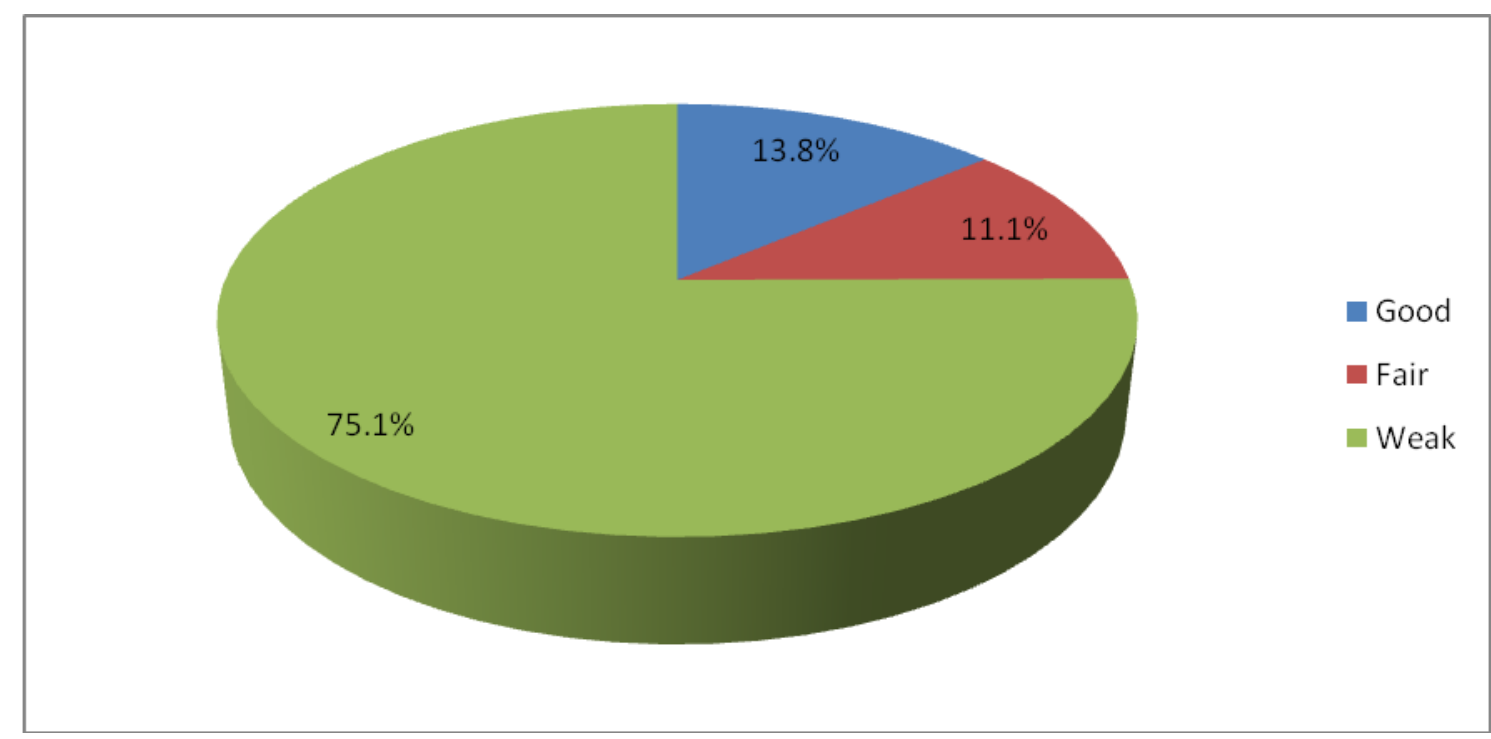

Figure 1: Generalized rating of funding of ADPs in Nigeria Source: NAERLS field survey

\section{Implications of the findings For ATA}

Research shows that the challenges affecting the performance and effectiveness of the ADP system in Nigeria include, among others, inadequate funding, coupled with neglect of the training and development needs of extension agents. These therefore call for government attention to address the above problems. In line with the federal government's dream of Agricultural Transformation Agenda, it implies that necessary steps must be taken in prospering solutions to the identified problems. Also, the decision has to be taken and workable policy set in place to adequately address agricultural extension delivery problems and capacity building of frontline EAs for the realization of this dream, which are highlighted below:

$>$ ADPs need to acquire the internal capacity to assess own trainings and development on a regular basis by adopting the training/ development analysis and planning as part of organizational design. This may facilitate the employees' learning through training so that their modified behaviour contributes to the attainment of the organization's goals and objectives.

$>$ Government should increase its funding of the ADPs to alleviate the problems of inadequate staff and insufficient training. Also, ADPs need to explore alternative sources and methods of sourcing funds for their operational services through partial commercialization of some of their services and encouragement of the private sectors to invest in agricultural information dissemination.

\section{Conclusion and recommendation}

This paper analysed the ADPs situation regarding training needs of extension agents and major contributor to the staffing and training problems in Nigeria. Majority of ADPs are week funded and inadequately staffed, who desperately need trainings in different subject areas. In this respect, ADPs and all actors involved in extension services delivery should be adequately funded and training for prospective professional attributes which should cover all the identified training provided. These trainings should be schedule and effectively carried out at various levels of extension personnel across the country to ensure the success and sustainability of federal government ATA. 


\section{References:}

Agricultural Extension Transformation Agenda implementation plan (2012) Memorandum by the Federal Ministry of Agriculture And Rural Development To The National Council On Agriculture at Enugu, March $13^{\text {th }}-15^{\text {th }}, 2012$

Albert, C.O. and Isife B.I eds (2009) Issues in Developing a National Policy on Agricultural Extension Service in Nigeria: The proceeding of Extension Professionals. Vol. 4, pp 2226 http://www.medwelljournals.com/author.php

Auta, S.J. and Dafwang II (2012). The Agricultural Development Projects (ADPs) in Nigeria: Status and Policy Implications. Res. J. Agric. Biol. Sci. 6(2) Pp 138-143.

Coutts, J., Roberts, K., Frost, F., and Coutts, A. (2005). The Role of Extension in Building Capacity - What works, and why. Retrieved 12 September 2007, from Rural Industries Research and Development Corporation Website http://www.rirdc.gov.au/reports/HCC/07-102.pdf

National Agricultural Extension and Research Liaison Services (NAERLS) and National Food Reserve Agency (NFRA) (2008). Pp 69 - 73

National Agricultural Extension and Research Liaison Services (NAERLS) and National Food Reserve Agency (NFRA) (2009). National report of agricultural performance survey of 2009 wet season in Nigeria. Pp 104-107,120 \& 121

National Agricultural Extension and Research Liaison Services (NAERLS) and National Food Reserve Agency (NFRA) (2010). National report of Agricultural performance survey of 2009 wet season in Nigeria. Pp $157-172$

National Agricultural Extension and Research Liaison Services (NAERLS) and National Programme on Agriculture and Food Security (NPAFS) (2011). National report of Agricultural performance survey of 2011 wet season in Nigeria. Pp $174-191$

National Agricultural Extension and Research Liaison Services (NAERLS), (2012). Executive summary of Agricultural performance survey of 2012 wet season in Nigeria. October,

Qamar, M. K. (2005) Modernising National agricultural extension system: Practical guides for policy-makers of developing countries. Research, Extension and Training Division Sustainable Development Department FAO.

Rogers, E. (1995). Diffusion of Innovation. New York: Free Press.

Ssekiboobo, A. M. and Muwanga-Zake, E.S.K. (2013) Prospects and Challenges of Training In Agricultural Statistics At Different Levels In A Developing Country typo3.fao.org/...and.../ICASV3.2112PaperMuwangaZake.pdf 